\title{
Metallurgical Research at the National Physical Laboratory
}

\begin{abstract}
VOL. 25 of the "Collected Researches of the National Physical Laboratory" (London : H.M. Stationery Office, 1935. 25s. net) contains some of the more important of the publications which have emanated from the Metallurgical Department during the last ten or twelve years. This volume of 432 pages shows how profound has been the influence that this Department has exercised, particularly perhaps in setting a standard for other workers to emulate. It is not too much to say that every one of the twenty-three papers now collected together is of real importance.
\end{abstract}

The work is concerned in the first place with the alloys of iron, not the least important of the contributions being those devoted to the preparation of the pure elements chromium, manganese and silicon. The essential part played by refractory materials in such research needs no stressing, and the paper on special refractories for this purpose contains information which will be of the greatest value to all workers in the higher temperature range.

Passing on to the consideration of the work on non-ferrous materials, three papers dealing with the silver - tin alloys and amalgams, which represent work carried out for the Dental Investigation Committee of the Department of Scientific and Industrial Research, lay down for the first time scientific foundations for the study of dental amalgam fillings. Although this work is at the present time in a rela- tively elementary stage, and far more intense research is required before many of the intriguing problems connected with these materials are solved, a most important commencement has been made.

Other papers are concerned with the transformations in the copper - gold alloys, the constitution and the physical properties of the alloys of cadmium and zinc, the properties of metallic cadmium, the crystal structures of $\alpha$ - and $\beta$-manganese, a new form of dilatometer and the surface tension of liquid metals. Particular attention may perhaps be directed to the last of these, since in addition to the measurement of the surface tension for a number of liquid metals and lead - tin alloys, the work has resulted in evidence to show that bismuth, cadmium and antimony may be highly associated in the liquid state. Anything which increases our knowledge, at the present time almost infinitesimal, of the condition of metals and alloys when molten, is most heartily to be welcomed.

Practically the whole of this work was carried out under the supervision of the late Dr. W. Rosenhain, and published whilst he was superintendent of the Department concerned, or soon after his retirement. Although his name occurs once only in this list of papers, and that in the introduction to the researches on the alloys of iron, the volume represents a lasting memorial to the influence which he exercised on research in his own Department, and through it, in most parts of the world.
F. C. T.

\section{Lunar Effects on Atmospheric Pressure}

$\mathrm{U}^{\mathrm{N}}$ NDER the heading "Effect of the Moon on Barometric Pressure" a summary appeared in NATURE of November 16, 1935, p. 800 of a paper by R. A. Robb and T. R. Tannahill" entitled "The Lunar Atmospheric Pressure Inequalities at Glasgow". A remarkable feature of their results, to which attention was directed, was the relatively large magnitude of the diurnal amplitude compared with that of the semi-diurnal amplitude, the two being in the ratio of more than four to one.

It now appears from a paper by Prof. S. Chapman ${ }^{2}$ that this result was due to the presence of a systematic source of error, arising from the plan that had been followed of rejecting all days from the analysis on which the difference of pressure between successive upper transits of the moon exceeded 0.1 inches of mercury. This plan resulted in the appearance of an effect known as the 'convex effect' to which Bartels directed attention in 1927. Such days of small pressure change occur more frequently when the barometer is above than below its normal level, and at such times the pressure curve is near a maximum value and tends to be convex ; it follows that in the long run a spurious maximum will be found near the middle of the lunar day, which in this case was reckoned to begin at the lunar upper transit, and that the spurious term will therefore have a phase angle somewhere near $270^{\circ}$.
Chapman points out that the first three harmonic components found by Robb and Tannahill, for which the amplitudes were $64,15 \cdot 6$ and 8.9 microbars, had phase angles of $267^{\circ}, 285^{\circ}$ and $292^{\circ}$ respectively, which illustrate the 'convex effect', and that the results obtained were substantially not of lunar origin. He states, however, that an earlier and hitherto unpublished analysis of the Glasgow data by Robb in 1926, made in such a way that the 'convex effect' was not present, showed correctly that the lunar atmospheric tide at Glasgow is, for the latitude, very small-of amplitude 4 or 5 microbars, that is, about a third of the ampli. tude at Greenwich and Aberdeen, as had been found by Chapman in the cases of Victoria and Vancouver.

Prof. Chapman has also recently discussed the lunar atmospheric tide in the Azores $^{3}$, using unpub. lished data for Ponta Delgada $\left(38^{\circ} \mathrm{N} ., 26^{\circ}\right.$ W. $)$ and Santa Cruz $\left(39^{\circ}\right.$ N., $31^{\circ}$ W.). Bi-hourly barometric data were employed, obtained in each ease by inter. polation from pressure read at $6,10,11,16$ and 21 hours from a Tonnelot compensated barometer with the aid of the continuous record of a Richard barograph, the analysis being made with the aid of Hollerith sorting and tabulating machines lent by the British Tabulating Machine Co. Ltd.

The results are shown by the values obtained for 